\title{
Erratum to: Refractory Characteristics of Aluminum Dross-Kaolin Composite
}

\author{
S.O. ADEOSUN, ${ }^{1,3}$ E.I. AKPAN, ${ }^{2,4}$ and M.O. DADA ${ }^{1,5}$ \\ 1.-Department of Metallurgical and Materials Engineering, University of Lagos, Lagos, Nigeria. \\ 2.-Department of Materials and Production Engineering, Ambrose Alli University, Ekpoma, \\ Edo State, Nigeria. 3.-e-mail: samsonoluropo@yahoo.com. 4.-e-mail: emma_eia@yahoo.com. \\ 5.-e-mail: modupeoladada@gmail.com
}

\section{Erratum to: JOM, Vol. 66, No. 11, 2014 \\ DOI 10.1007/s11837-014-1179-5}

In the original published version of this article, reference number 12 was cited incorrectly. The correctly cited reference is below:

C. Dai (M.S. thesis, Department of Material Science Engineering, Worcester Polytechnic Institute, Worcester, MA, 2012). 